\title{
Influence of Electrolytic Conditions on the Preparation of NiOOH by Catalytic Electrolysis Method
}

\author{
Yanzhi Sun ${ }^{1}$, Nana Liu', Junqing Pan ${ }^{1,2, *}$, Pingyu Wan $^{1}$ \\ ${ }^{1}$ National Fundamental Research Laboratory of New Hazardous Chemicals, Assessment and Accident \\ Analysis, Beijing University of Chemical Technology, Beijing 100029, China \\ ${ }^{2}$ State Key Laboratory of Chemical Resource Engineering, Beijing University of Chemical \\ Technology, Beijing 100029, China \\ *E-mail: jqpan@mail.buct.edu.cn
}

doi: $10.20964 / 2018.03 .25$

Received: 13 September 2017 / Accepted: 28 December 2017 / Published: 5 February 2018

\begin{abstract}
In this paper, we propose a new method for the preparation of spherical nickle oxyhydroxide (NiOOH) by a clean catalytic electrolysis process of spherical $\mathrm{Ni}(\mathrm{OH})_{2}$ in alkaline solution. The influence of various parameters, such as kinds of catalysts, reaction temperature and electrolysis duration on electrolysis is studied and the catalytic electrolysis mechanism is discussed. The prepared $\mathrm{NiOOH}$ sample is characterized by X-ray diffraction, scanning electron microscope observation and electrochemical measurements. The experimental results show that the spherical $\beta$-NiOOH powder with high capacity is obtained by electrolysis process under the conditions of a temperature of 30-35 ${ }^{\circ} \mathrm{C}$ with addition of $\mathrm{KMnO}_{4}$ for $4 \mathrm{~h}$ in $6-9$ mol L ${ }^{-1} \mathrm{NaOH}$ solution. The obtained $\mathrm{NiOOH}$ electrodes have superior electrochemical performance than commercial $\mathrm{MnO}_{2}$ electrodes under different current densities. The $\mathrm{NiOOH}$ electrode offers $273.6 \mathrm{mAh} \mathrm{g}^{-1}$ specific capacity at $60 \mathrm{~mA} \mathrm{~g}^{-1}$, which is about $20 \%$ higher than that of commercial $\mathrm{MnO}_{2}$ electrode.
\end{abstract}

Keywords: Nickle oxyhydroxide; $\mathrm{KMnO}_{4}$; Catalytic electrolysis; $\mathrm{Ni}(\mathrm{OH})_{2}$

\section{FULL TEXT}

(C) 2018 The Authors. Published by ESG (www.electrochemsci.org). This article is an open access article distributed under the terms and conditions of the Creative Commons Attribution license (http://creativecommons.org/licenses/by/4.0/). 